\title{
Practice-based Research Networks (PBRNs) in the United States: Growing and Still Going After All These Years
}

\author{
John Hickner, MD, MSc, and Larry A. Green, MD
}

Ten years have passed since we wrote "A Short History of Primary Care Practice-based Research Networks: From Concept to Essential Research Laboratories." In that essay we described the roots of general practice research in the work of visionary family physicians James Mackenzie, Will Pickles, John Fry, F. J. A. Huygen, and Curtis G. Hames. We discussed the early efforts in the 1960s and 1970s to aggregate data across many practices in the United Kingdom, The Netherlands, and Australia to understand the epidemiology of primary care. More than 40 years ago J. Perry reported on the development of the Oxford Record Linkage Study, which sounds much like contemporary projects designed to understand the health problems and health care of populations. ${ }^{2}$

Regional Practice-Based Research Networks (PBRNs) got off the ground in the United States in the 1970s in Colorado (The Family Medicine Information System) and New England (The Cooperative Information Project). A major PBRN breakthrough was the launch of the Ambulatory Sentinel Practice Network (ASPN) in 1981, a binational network spawned by members of the North American Primary Care Research Group, which included many private and academic practices in the United States and Canada. ASPN was a prolific primary care research organization, publishing seminal work that changed practice, including debunking the recommendation for brain computed tomography (CT) for adults with new-onset headache and the recommendation for routine dilation and curettage $(\mathrm{D} \& \mathrm{C})$ for spontane-

From the University of Illinois at Chicago College of Medicine, Chicago (JH); and University of Colorado School of Medicine, Aurora (LAG).

Funding: none.

Conflict of interest: none declared.

Corresponding author: John Hickner, MD, MSc, Department of Family Medicine, University of Illinois at Chicago, 1919 W Taylor Street, Chicago, IL 60612 (E-mail: hickner@uic.edu). ous abortion. ${ }^{3,4}$ ASPN morphed into the American Academy of Family Physicians National Research Network in 1999 and continues to do outstanding primary care research.

As 2 family physicians who have participated in the PBRN movement for the past 35 years, in this commentary we offer some reflections on the continued evolution of PBRNs. We suggest "what is the same" and "what is new" with PBRNs, followed by some thoughts about the future of these essential laboratories for family medicine and primary care. The substrate for these reflections is our own personal experience, conversations with others in the PBRN community and a stroll through the studies published in this issue of $7 A B F M$, which evoked many of our thoughts.

\section{What Is the Same?}

Practice-based research networks are alive and well and continue to do important work to understand and to improve primary care practice and its intersections with specialty care, public health, and our communities. There is evidence to support this assertion. In 1994 we could identify 28 PBRNs in the United States. In 2003 there were 111 PBRNs registered on the Agency for Healthcare Research and Quality (AHRQ) website, and now there are 169. These networks are conducting research studies and publishing their work. Although the list is likely incomplete, the AHRQ PBRN Research Bibliography lists more than 100 publications from PBRNs every year since 2005, peaking at 220 in 2010 (http://pbrn.ahrq.gov/pbrn-literature).

There is still great need to understand the epidemiology of primary care practice and personoriented outcomes of care. The studies in this issue of $7 A B F M$ display the continuing importance of descriptive research using the naturalistic, observational opportunities inherent in frontline practice 
derived from knowing the patients and their problems and observing how health is won and lost. The new national Swiss network is a reminder that sentinel surveillance of primary care practice remains a critical function for PBRNs. ${ }^{5}$

There remains a tension concerning generalizability of results from PBRN studies about phenomena as they occur in practice, with built in selection and observer bias. PBRNs study health care as it unfolds daily in real-world practices in diverse communities. PBRNs thrive on their own selection biases-it is part of what makes them (and their pragmatic trials) important. Traditional randomized trials also have difficulty with generalizability because trials often exclude most of the population for which results are intended. PBRNs continue to wrestle with translation of knowledge acquired elsewhere to the frontlines of health care. People still wait for care that matches their situations.

What makes a PBRN a PBRN is the same now as it was in the beginning. The essence of PBRNs is that the relationships formed among the investigators, network administrators and practitioners and their office staffs are expected to endure over time and independent of the topic of interest, with active participation of practice members at all stages of study development, implementation and reporting.

Many of the conditions PBRNs study have stayed amazingly consistent and constant for more than 30 years. This is no surprise because the primary care problems of the people served do not change much over time. Primary-care practices are continually confronted with acute illness, chronic disease, mental health issues, and the social determinants of illness. Kudos to Shared Networks of Collaborative Ambulatory Practices and Partners (SNOCAP), who demonstrated that a PBRN can improve control of diabetes and hypertension. ${ }^{6}$

Some studies in this issue of $7 A B F M$ are not from PBRNs, but they required practice-based research to get to results critically important to practice and policy. ${ }^{7,8}$ As has been the case for centuries, not all primary-care research requires a PBRN. PBRNs are still essential laboratories for primary care research but not the exclusive venue.

Unfortunately, PBRN research and primarycare research in general remain fragile and woefully underfunded. Nearly every year, including 2015, the U.S. Congress threatens to shut down or se- verely limit funding of the AHRQ, the only federal funding source that has taken an enduring active interest and leadership role in PBRN research. Intrepid PBRNs and primary care researchers march on, doing important, desperately needed work on shoestring budgets.

\section{What's New?}

Two events have profoundly affected the research agenda of PBRNs: publication of the companion reports, To Err Is Human ${ }^{9}$ and Crossing the Quality Chasm $^{10}$ in 1999 and 2001, and the passage of the Patient Protection and Affordable Care Act (ACA) in 2010. Before these reports, practice systems improvement was not so high on the agenda of PBRNs, but it has come to the forefront as the transformation of U.S. primary care practices has proceeded to become safer, more timely, more patient centered, more effective and efficient, and more equitable.

The ACA has increased demand for robust primary care and simultaneously accelerated the consolidation of large health systems and the employment of primary care clinicians by these large health care systems. These have been a doubleedged sword for PBRNs. Time that once could be spent on practice-based research has often been trumped by the immediate needs of increased patient-care demands. Decision making about PBRN studies changed, including a loss of autonomy at the local practice level that can create another drag on PBRN research. It can be more difficult to convince large health care organizations rather than local, small- or medium-sized practices of the value of participating in studies to understand and to improve primary care practice. And, there are often challenges in decision making about studies and implementation of studies secondary to consolidating entities, electronic health records (EHR) vagaries, and big systems with a spectrum of possibly conflicting goals.

In contrast, if a large health care organization "gets it" and values practice-based investigations, additional resources may be available as part of core business to support projects seen as quality and practice improvement. Of course, large health care organizations have many patients and hundreds of thousands of individuals' health records in electronic format, providing an ideal opportunity to study the epidemiology and outcomes of primary 
care practice. Once the full potential emerges for recording, linking, and aggregating data on individuals, their signs and symptoms and conditions, their communities, care processes, and outcomes, EHRs and associated data warehouses will provide powerful tools to accelerate advanced PBRN research. Emerging vanguard national networks such as the Practice Partners Research Network, DartNet, the Health Care Systems Research Network, and others are developing and using new tools to extract and aggregate data residing in electronic health records to study primary care, the largest platform of health care delivery on a grand scale.

Another new development is the use of increasingly sophisticated and varied scientific methods by PBRNs. Analyzing and making sense of large, practice-based data sets requires the always evolving analytic methods to cope with bias and error. Large, pragmatic trials with few exclusions and straightforward outcomes can be accomplished at lower cost in large, electronically linked networks, leading to greater external validity.

Regardless of large system or small practice, implementing and sustaining high-quality care for all patients is now at the center of PBRNs' research efforts. Many are shifting efforts from a single disease focus per study to practice systems transformation to improve care across a wide range of conditions. An example is the Fernald et al study, ${ }^{11}$ which shows PBRN persistence through a 3-stage project yielding a toolkit to improve testing: to move the dial on hypertension and diabetes measures. This same study also reminds us how important it is to map practice processes and how difficult it can be to complete practice-based research. Thirty-one practices were recruited, 24 consented, 22 actually participated, 20 did something, and only 4 practices were able to complete the 6-week intervention for quality improvement. This reported experience provides additional evidence for the need for a "primary care extension service" to support practice transformation, as proposed by Grumbach and Mold. $^{12}$

A welcome new trend on the PBRN scene is the inclusion of patients as research partners, pioneered by Jack Westfall and colleagues ${ }^{13}$ at the High Plains Research Network. This network's patient advisory council formulates questions with investigators, designs studies together, interprets results together, and sculpts dissemination of results so they get to who needs to know them. This is a truly patient-centered approach. In this issue, the study by Goodman et $\mathrm{al}^{14}$ to validate a simple literacy measure in primary care is evidence of the recognition that patients must be partners in their care.

\section{The Future: Speculations Genetics}

There is an alliance to be forged between those exploring genotypes and those living with phenotypes. Genomics, proteomics, and pharmacogenomics are a routine part of modern oncology practice, and applications for everyday primary care are likely to arrive in the next decade. PBRNs are well positioned to participate in getting it right to avoid over- and underutilization of these new technologies.

\section{Linkage With Public Health}

The movement toward linkages between primary care and public health on behalf of population health is another promising, emerging development in the PBRN community that has been supported in part by the National Institutes of Health Clinical Translational Sciences Awards program. As discussed in the 2012 Institute of Medicine report $^{15}$ and the Practical Playbook, ${ }^{16}$ integrating primary care and public health represents a huge opportunity for PBRNs.

\section{Integrating Primary Care and Behavioral Health}

It is unlikely that better, affordable health care that improves health will be achieved until the artificial boundary between primary care, mental health and behavioral health is replaced with integrated practice. It can be done, and widespread implementation represents another major opportunity for PBRNs. ${ }^{17}$

\section{Policy Development and Assessment}

Practice-based research is critical to policy assessment as well, as we can see from 2 studies in this issue of $7 A B F M .^{7,8}$ PBRNs can help assess effect of policies at local levels as well, in addition to their mandate to improve primary care at the practice level. ${ }^{7}$ And federal policy and programs can have an effect on local practices, as noted in the report of the Beacon project. ${ }^{8}$ This study shows the power of uniform data systems and reveals the continuing opportunity for PBRNs to study effects of EHRs. 


\section{More attention to definitions, classification, data models, and measures}

The boundaries among evaluation, research, practice improvement, and quality improvement have become permeable to one another. The regulatory environments and methods associated with these historic terms can be expected to adapt to the emerging world of practice-based research. With the implementation of the International Classification of Disease v. 10 (ICD-10) there will be a renewed interest in classification and terminology. A shared data model could prove to be foundational for PBRNs and primary care research. ${ }^{18}$

\section{Testing Guidelines in Unselected Populations}

The movement toward practice transformation and implementation research to "close the quality gap" is necessary, but does have a dark shadow. Many guidelines do not have a solid scientific evidence base, and it is concerning if PBRNs believe that that work is complete when guideline adherence is high. There is still a great need to challenge conventional wisdom with solid data, as ASPN did when it demonstrated the lack of need for computed tomography (CT) scans for new-onset headache and D\&C for spontaneous abortion. Some of the current chronic kidney guidelines, for example, are based on expert opinion rather than solid epidemiologic, patient-oriented outcomes. PBRNs should be testing these guidelines to see what is important for patients and what is not. Which elements of the guidelines actually lead to improved patient-oriented outcomes, such as dialysis and kidney transplant, rather than a better creatinine clearance?

\section{Alignment of PBRNs and Maintenance of Certification}

The American Board of Medical Specialties' 2015 standards for all medical specialties are headed toward full implementation, and they focus on much more than knowing things and taking tests-specifically, actually improving practice. The American Board of Family Medicine is proceeding apace with testing new registries and data acquisition and management tools to enable more than 86,000 board-certified family physicians to assess their local practice and measure effects of improvement strategies. ${ }^{19}$ As this matures, it will probably be time to convene a summit to reimagine the struc- ture and functions of primary care practice-based research networks.

\section{Concluding Comments}

Once again we see the stunning complexity of primary care and the meagerness of the infrastructures to discover and support it. The resilience, adaptability, and continued expansion of PBRNs is on display in this issue of $7 A B F M$. This is good news for those seeking transformation of health care such that it actually matches patients' goals and needs and improves both individual and population health. It is obvious that PBRNs remain an important part of the U.S. research landscape. Those clinicians, patients, and investigators working within them have established a way of life that is adaptive, underappreciated, and rich with opportunity. Surely the time when proper financial support for practice-based research becomes part of practice business models and a priority for the medical research enterprise is closer than ever. It cannot come too soon.

\section{References}

1. Green LA, Hickner J. A short history of primary care practice-based research networks: from concept to essential research laboratories. J Am Board Fam Med 2006;19:1-10.

2. Perry J. Medical information systems in general practice-A community health project. Proc R Soc Med. 1972;65:241-2.

3. Spontaneous abortion in primary care: A report from ASPN. J Am Board Fam Pract. 1988;1:15-23.

4. Becker LA, Green LA, Beaufait D, Kirk J, Froom J, Freeman WL. Use of CT scans for the investigation of headache: A report from ASPN, Part 1. J Fam Pract 1993;37:129-34.

5. Selby K, Cornuz J, Senn N. Establishment of a representative practice-based research network for the monitoring of primary care in Switzerland. J Am Board Fam Med 2015;28:673-5.

6. DeAlleaume L, Parnes B, Zittleman L, et al. Success in the Achieving CARdiovascular Excellence in Colorado (A CARE) home blood pressure monitoring program: A report from the Shared Networks of Colorado Ambulatory Practices and Partners (SNOCAP). J Am Board Fam Med 2015;28: $548-55$.

7. Liaw W, Moore M, Iko C, Bazemore A. Lessons for primary care from the first ten years of Medicare coordinated care demonstration projects. J Am Board Fam Med 2015;28:556-64.

8. Jones $\mathrm{E}$, Wittie $\mathrm{M}$. Accelerated adoption of advanced health information technology in Beacon commu- 
nity health centers. J Am Board Fam Med 2015;28: $565-75$.

9. To Err Is Human: Building a Safer Health System. National Academy Press, 1999.

10. Crossing the Quality Chasm: A New Health System for the $21^{\text {st }}$ Century. Washington, DC: National Academy Press, 2001.

11. Fernald D, Hamer M, James K, Tutt B, West D. Launching a laboratory testing process quality improvement toolkit: From the Shared Networks of Colorado Ambulatory Practices and Partners (SNOCAP). J Am Board Fam Med 2015;28:576-83.

12. Grumbach K, Mold JW. A health care cooperative extension service: transforming primary care and community health. JAMA 2009;301:2589-91.

13. Westfall JM, Ingram B, Navarro D, et al. Engaging communities in education and research: PBRNs, AHEC, and CTSA. Clin Transl Sci 2012;5:250-8.

14. Goodman MS, Griffey RT, Carpenter CR, Blanchard M, Kaphingst KA. Do subjective mea- sures improve the ability to identify limited health literacy in a clinical setting? J Am Board Fam Med 2015;28:584-94.

15. Primary Care and Public Health: Exploring Integration to Improve Population Health. Washington, DC: National Academy Press, 2012.

16. A practical playbook. Available from: https://www. practicalplaybook.org.

17. Melinda Davis M, Balasubramanian B, et al. Integrating behavioral and physical health care in the real world: Early lessons from advancing care together. J Am Board Fam Med 2014;27:161.

18. Green LA, Klinkman M. The foundational and urgent importance of a shared primary care data model. Ann Fam Med 2015;13:305-11.

19. The Summer 2015 edition of the Phoenix. A Diplomates' newsletter. Available from: https://www. theabfm.org/about/news070215.aspx. Accessed on July 8, 2015. 